\title{
Hello pension, goodbye tension? The impact of work and institutions on older workers' labor market participation in Europe
}

\author{
By Maria FleischmanN ${ }^{1}$, Ferry KOSter ${ }^{1,2}$, \\ PEARL DYKSTRA ${ }^{1}$ E JOOP SCHIPPERS ${ }^{3}$
}

\begin{abstract}
To sustain the welfare state, several EU countries agreed to take measures aimed at increasing the labor market participation of older workers (European Commission 2001). In this study, we developed a framework integrating individual, work, and institutional characteristics in order to explain the labor market participation of older workers. While prior studies focused mainly on individual characteristics, the present analysis investigated the impact of work and institutions more closely using the European Social Survey. Multilevel analyses across 21 countries showed that work characteristics increased the benefits from work, hence increasing the likelihood of participation among older workers, and that the generosity of institutions discouraged older workers to remain in the labor market.

Keywords: labor market participation, older workers, work characteristics, pension benefits, comparative research.

\footnotetext{
${ }^{1}$ Maria Fleischmann, Ferry Koster \& Pearl Dykstra, Department of Sociology, Faculty of Social Sciences, Erasmus University Rotterdam, Rotterdam, The Netherlands

${ }^{2}$ Ferry Koster, Amsterdam Institute for Advanced Labour Studies (AIAS), University of Amsterdam, Amsterdam, The Netherlands
}

${ }^{3}$ Joop Schippers, Department of Economics, Utrecht University, Utrecht, The Netherlands
\end{abstract}


International Journal of Ageing and Later Life

\section{Introduction}

After a peak in the 1970s, the labor participation of older workers decreased rapidly, mainly because of the economic crisis and a diminishing demand for labor. Besides that, retirement schemes expanded and the general belief took hold that everyone should be able to enjoy the "golden years" of retirement (Van Dalen et al. 2006). However, with the aging of the population, one of the most pressing policy questions concerns retirement schemes in the near future (European Commission 2009; Komp \& Béland 2012; Walker \& Maltby 2012; Wise 2010). One policy response is reflected in the Stockholm target in which countries agreed to increase the labor market participation of older workers (55-64 years) to a level of $50 \%$ by 2010 (European Commission 2001). After the target year 2010, some countries achieved the $50 \%$ target; however, despite the agreement among the EU countries, great differences between countries persist. While in 2010 the labor market participation of older workers was about $70 \%$ in Sweden and Norway, it was about or below $30 \%$ in, for example, Austria, Belgium, or Poland (see Appendix C, Eurostat 2012).

Existing studies showed that individual, work, and institutional characteristics were related to the labor market participation of older workers (Blöndal \& Scarpetta 1999; European Commission 2009; Liefbroer 2009; OECD 2011). Regarding individual characteristics, it was found that early retirement is higher among employees with poor health (Hayward et al. 1989, 1998; Mein et al. 2000; Schils 2008; Von Bohnsdorff 2009) and among women (Blöndal \& Scarpetta 1999; European Commission 2009; OECD 2011). Besides that, human capital played a role. Job tenure was associated with a higher probability of non-participation (Hayward et al. 1989, 1998; Schils 2008). Education effects, however, turned out to differ between countries. While higher education was associated with later retirement in the UK (Schils 2008), the US (Hayward et al. 1989, 1998), and Norway (Blekesaune \& Solem 2005), studies in other countries reported the opposite effect (Fischer \& Sousa-Poza 2006). Finally, family and partners play a role: individuals who had a partner and those with children appeared to retire earlier in some countries (Damman et al. 2009; Schils 2008). Moreover, different strands of literature discussed that individual 
retirement decisions were often taken as a joint decision of spouses (see e.g., Blau 1998; Coile 2004) and that informal care obligations affected retirement planning (see e.g., Dentinger \& Clarkberg 2002). With regard to work characteristics, studies showed that physical demand (Blekesaune \& Solem 2005; Hayward et al. 1989, 1998) and part-time work (Damman et al. 2009; Hayward et al. 1998) decreased labor market participation. Findings regarding compensation were not straightforward. While higher hourly wages were related to earlier retirement in the US (Hayward et al. 1989, 1998) and the UK (Schils 2008), this association was the opposite in The Netherlands and Germany (Schils 2008). Also, there was some evidence showing that wealth related to later retirement (Damman et al. 2009). Results regarding institutional characteristics showed that a higher unemployment rate in a country and a lower gross domestic product (GDP) per capita was associated with earlier retirement, while employment protection did not affect early retirement (Blöndal \& Scarpetta 1999; Fischer \& Sousa-Poza 2006; Kim 2009).

The present study extends these prior investigations as follows. First, we aim at combining the results from previous work by using an integrated theoretical framework. The starting point of this model is the idea that individuals' decisions are (bounded) rational. This means, individual, work, and institutional characteristics might affect the utility (a benefit) or disutility (a cost) that individuals derive from participating in the labor market. By doing so, the analyses presented combine theoretical insights that explain individuals' labor market participation but have been treated separately to date. By including several work and institutional characteristics that have not been investigated before, the present study is wider in scope than earlier studies. In our theoretical model and the analyses, we include work characteristics, more specifically job resources, job demands, and work values; these were found to affect voluntary turnover but have not yet been used to explain the labor participation of older workers (Bakker \& Demerouti 2006; Beehr 1986; Fasang et al. 2012; Forma 2008; Hayward et al. 1998; Lambert et al. 2001; Mein et al. 2000; Shultz et al. 1998; Siegrist \& Wahrendorf 2010; Siegrist et al. 2006; Smith et al. 2011; Van den Broeck et al. 2011; Wang \& Shultz 2009). 
International Journal of Ageing and Later Life

With regard to the institutional characteristics, this study provides two contributions. By including 21 European countries, the analyses are conducted on a broader range of countries than prior studies (Fischer \& Sousa-Poza 2006; Kim 2009; Schils 2008; Siegrist \& Wahrendorf 2010; Van Oorschot \& Jensen 2009), thus enabling us to test more rigorously the link between macro level institutions and individual labor market behavior using multilevel analysis. Moreover, instead of focusing on general country characteristics such as GDP per capita, specific arrangements affecting older workers' labor market participation are taken into account, namely the generosity of retirement schemes and the labor market situations in the countries.

The resulting hypotheses are tested using the second wave of the European Social Survey (ESS 2004). We complement these data with pension indicators that were developed within the MULTILINKS project (Keck et al. 2009) and data from Eurostat and the OECD with information on the labor market situation. The total dataset includes information on 15,045 individuals from 21 European countries.

\section{Theoretical Framework of Labor Market Participation}

To arrive at a theoretical framework for the labor market participation of older workers, we start with the basic idea of labor supply in which individuals weigh the costs and benefits of participating (Wang \& Shultz 2009). With regard to older workers, a central decision concerns the question whether one wants to stay in the labor market or withdraw from it through (early) retirement. In order to model the decision of whether or not to participate by means of a rational choice (Coleman 1990; Wang \& Shultz 2009), individual, work, and national characteristics are assumed to provide a certain (dis)utility for participation (see Figure 1). The basic assumption is that the participation of older workers depends on the balance of utility and disutility derived from work. As long as the benefits of participation outweigh the costs, older workers will choose to remain in the workforce. This means that utility leads to participation and disutility contributes to non-participation.

In the present analysis, work and institutional characteristics are included based on the (dis)utility they offer to individuals. As individual 
Hello pension, goodbye tension?

Figure 1. Individual, work and institutional factors relating to older workers' labor market participation

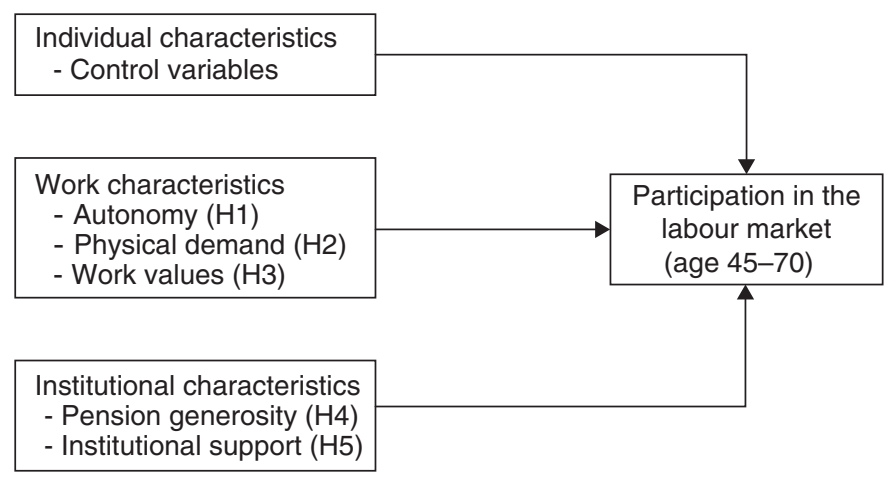

characteristics have been addressed in earlier research (Blöndal \& Scarpetta 1999; Damman et al. 2009; European Commission 2009; Fischer \& Sousa-Poza 2006; Hayward et al. 1989, 1998; Mein et al. 2000; OECD 2011; Schils 2008; Von Bohnsdorff 2009), we will not formulate specific hypotheses about their association with participation, but take them into account as control variables. First, the literature identified several so-called push and pull factors. Push factors, like bad health and bad jobs, move people towards retirement and pull factors, like welfare state arrangements, are circumstances providing an incentive for non-participation (Blekesaune \& Solem 2005; Hofäcker \& Pollnerova 2006; OECD 2006, 2011; Van Oorschot \& Jensen 2009). In the model proposed here, we regard push and pull factors as a disutility from work.

Secondly, the Job Demands-Resources (JD-R) model of work also fits the (dis)utility framework (Bakker \& Demerouti 2006; Fasang et al. 2012). Job demands refer to "physical, psychological, social, or organizational aspects of the job that require sustained physical and/or psychological (cognitive and emotional) effort or skills and are therefore associated with certain physiological and/or psychological costs" (Bakker \& Demerouti 2006: 321). Examples of job demands are work pressure and high physical efforts. Job resources in contrast are "physical, psychological, social, or 
International Journal of Ageing and Later Life

organisational aspects of the job that are [...] (1) functional in achieving work goals; (2) reduce job demands and the associated [...] costs; (3) [or] stimulate personal growth, learning, and development." (Bakker \& Demerouti 2006: 321). Career opportunities and autonomy are examples for job resources. While job demands refer to work-related characteristics that involve costs, job resources raise the benefits of the job. This way, job demands reduce the supply of labor due to the costs they involve, while job resources increase the supply of labor due to the benefits they accompany.

Thirdly, part of the literature examines the relationship between intrinsic and extrinsic work values and labor market participation (Frey 1997; Van den Broeck et al. 2011). These values can also be interpreted in terms of the utility that people derive from work, increasing their labor supply. This is based on the idea that individuals who value certain aspects of their work more derive a higher utility from work (Knoop 1994; Van den Broeck et al. 2011). Regarding their decision of whether or not to participate in the labor market, this means that they, due to the positive values, have higher incentives to remain in employment compared to those who do not intrinsically or extrinsically value their work.

\section{Work-Related Characteristics}

Job resources and individual resources can be regarded as a resource for older workers that increase the utility they derive from labor market participation. We regard autonomy in the workplace as a job resource and hypothesize that older employees are more likely to participate in the labor market if they have more autonomy in their job (autonomy hypothesis).

To a certain extent, job demands can contribute to the utility from work, as a challenging job can be interesting for employees. Nevertheless, if the challenges are too high, they turn into disutility from work. One clear example of job demands is the physical demand that workers experience in their work. We hypothesize that older employees are more likely to participate in the labor market if their job is less physically demanding (physical demand hypothesis).

Intrinsic and extrinsic values (Frey 1997; Ingelhart 1990) can increase the utility that people derive from work (Knoop 1994; Van den Broeck et al. 2011) and thus affect labor market participation. People who are motivated 
by intrinsic aspects of the job, such as having interesting work, find the content of the job and the possibilities for development important. Extrinsic values in contrast concern the importance of aspects such as receiving status or high earnings. It should be noted that intrinsic and extrinsic values do not have to contradict each other; employees can be motivated by both of them at the same time (Feather \& O'Brien 1986). Intrinsic values can be identified as personal resources (Van den Broeck et al. 2011), because they provide a utility to participate in the labor market by lowering levels of stress (Knoop 1994). And, extrinsic values contribute to the utility from work as people will have little access to these aspects outside work. Our next hypothesis therefore reads that older employees are more likely to participate in the labor market if their intrinsic or extrinsic work values are higher (work values hypothesis).

\section{Institutional Characteristics}

At the national level, there are different institutional characteristics that may affect individuals' (dis)utility derived from work. Here, we focus on two classes of these institutional differences between countries.

The disutility from work can be related to the level of "decommodification" of the welfare state (Esping-Andersen 1990), meaning that countries can be distinguished based on how important it is for a person to have work in order to have an income. In other words, decommodification is high if welfare state benefits are encompassing and available to a broad group of people. A high decommodification appears in most socialdemocratic states, like Sweden or Finland. On the contrary, liberal welfare states, such as the United Kingdom or the United States, generally provide less encompassing welfare benefits that are available to fewer people. As pensioners are (at least partly) dependent on retirement benefits provided by the social benefit system of their country, the generosity of these benefits will promote differences between countries with regard to the participation rate of older workers. For example, the official retirement age, the mean retirement age or the minimum contribution period in a country can provide information on the "availability" of retirement benefits. The countries' net replacement rate or their minimum pension level gives insight into the coverage of the welfare state or its financial "generosity." In more generous welfare states, benefits will be available more easily and 
International Journal of Ageing and Later Life

retirement will be financially more attractive. Following this argumentation, we hypothesize that older employees are more likely to participate in the labor market if the retirement benefits of the country are less generous (with respect to availability and coverage) (pension generosity hypothesis).

Next to differences in the countries' pension systems, the European countries have different types of labor markets, which as such provide varying utilities for individuals' labor market participation. The labor market characteristics of a country are a mixture of formal and informal institutions, such as policies concerning labor market protection, the unemployment rate among older workers, and the greying of the population. These institutional characteristics can be regarded from both a demand and supply perspective. On the one hand, a higher unemployment rate in the country might reduce workers' likelihood to supply labor. On the other hand, a higher unemployment rate might indicate that labor demand is lower. Additionally, these formal and informal norms may also reflect the public opinion about older workers. For example, if their employment position is protected, this may mean that more people are in favor of labor participation of older workers; and, in countries where more older worker participate, societal norms may also be more supportive. This way, the costs of workers' labor participation are reduced. We therefore hypothesize that older employees are more likely to participate in the labor market in countries with more formal and informal norms directed towards participation of older workers (institutional support hypothesis).

\section{Data}

To test the hypotheses, we used the second round of the European Social Survey (ESS 2004). We decided to use the second round, because, firstly, these data included the necessary individual information, such as labor market participation and work characteristics like individuals' motivation. And secondly, the 2004 data of the ESS allowed adding rich institutional level information from different sources. We added macro-level indicators that were established within the MULTILINKS project providing information about different welfare state characteristics, such as the official retirement age in a country for men and women and the net replacement rate for different career paths (Keck et al. 2009). Furthermore, we made use 
of country characteristics retrieved from the Eurostat and the OECD website. All country characteristics referred to 2004, the same year the ESS data were collected.

The second round of the ESS encompasses about 47,500 respondents from 25 European countries. Since country level data were not available for Switzerland, Iceland, Turkey, and the Ukraine, respondents from these countries were excluded. We furthermore restricted the analyses to older workers (aged 45-70 years). We chose 70 years as an upper limit, because even though the official retirement age is 65 years in most European countries, people can participate beyond the official retirement age. Last, we chose to include individuals who have not been retired longer than ten years. As a result, our analyses refer to 15,045 respondents from the following 21 countries: Austria, Belgium, Czech Republic, Germany, Denmark, Estonia, Spain, Finland, France, Great Britain, Greece, Hungary, Ireland, Luxembourg, the Netherlands, Norway, Poland, Portugal, Sweden, Slovenia, and Slovakia.

\section{Operationalization}

\section{Dependent Variable: Labor Market Participation}

The dependent variable labor market participation was generated using the variable asking the respondents about their main activity in the labor market. Those indicating to be "in paid work (or away temporarily) (employee, selfemployed, working for your family business)" or "unemployed and actively looking for a job" were coded as participating and those not participating include the categories "unemployed, wanting a job but not actively looking for a job," "permanently sick or disabled," "retired," or "doing housework, looking after children or other persons." This operationalization is usually used to distinguish the active (labor force) population from the inactive population (Eurostat 2013). As stated above, we only included respondents who were between 45 and 70 years of age. Furthermore, we excluded respondents who had been retired for more than ten years. We did this because some work characteristics were asked for the last (or current) job. Respondents who were already retired thus provide information on their last job. By only including those who retired 
International Journal of Ageing and Later Life

Figure 2. Labor market participation of workers aged 45-70 in seven European countries and the average ESS participation. ESS 2004, own analyses

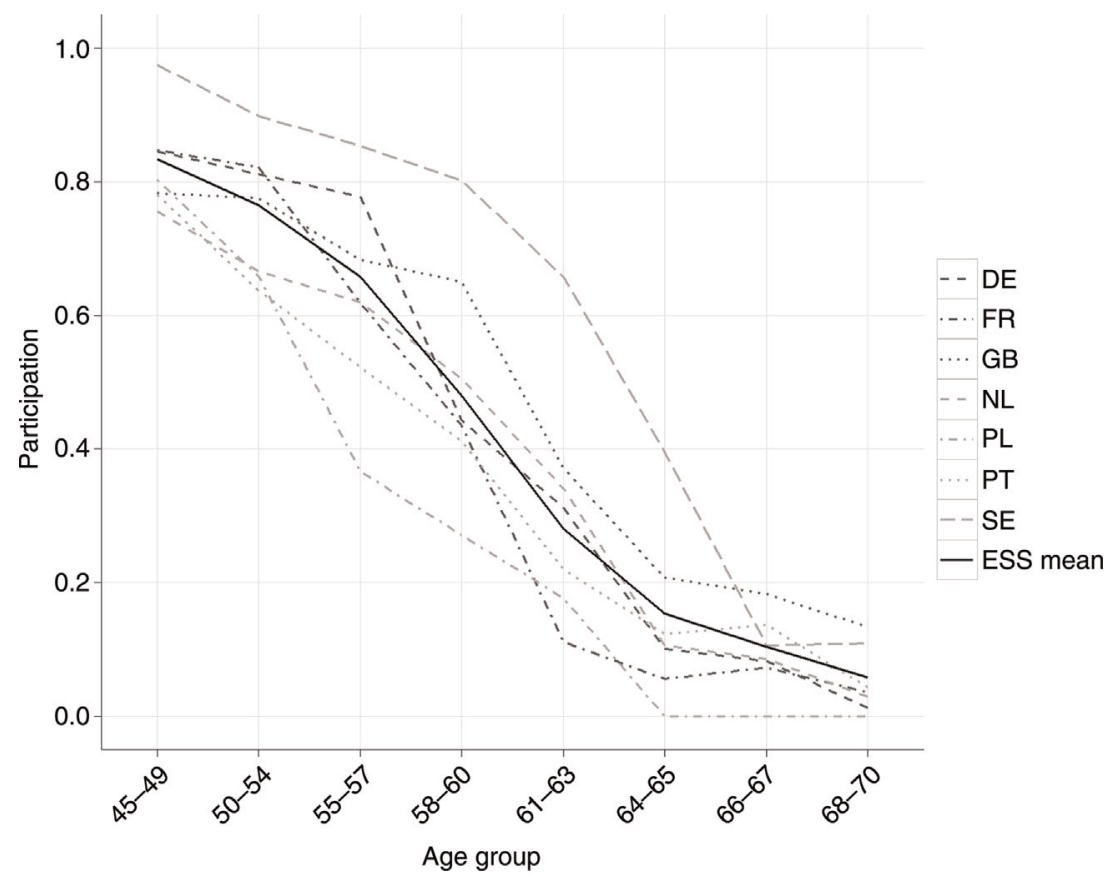

more recently, we aim at including information that is as reliable as possible. Robustness checks including respondents who retired five years ago or less are also discussed in the results section, but not reported due to space considerations.

Based on the ESS data used in this paper, we show in Figure 2 how participation of our sample $(\mathrm{N}=15,045)$ decreases with increasing age. We depict the participation rates for the same eight age categories that are also used in the explanatory analyses (compare Tables 1 and 2). In general, this figure shows that labor market participation declines with the increasing age of workers. The black solid line signifies the average participation for 
the 21 countries included in our analyses. Between age 45 and 49, more than $83 \%$ of the respondents are participating in the labor market. This percentage is only $50 \%$ for those aged $58-60$. In the oldest age group, only about $6 \%$ of the ESS respondents participate. Furthermore, we depict the participation in seven countries, namely Germany, France, Great Britain, the Netherlands, Poland, Portugal and Sweden, to show how great the variation is between countries. In Sweden (light gray, long dashed line), participation is highest of all countries in all age groups until age 65, while participation is generally lowest in Poland (light gray, dash dotted line). In our sample of the ESS data, the labor market participation of Polish respondents above the age of 64 years is zero. This reflects the very low average exit age from the labor force in Poland, which was 57.7 in 2004 (Eurostat 2013) and to a lesser extent also the low official retirement age of women, which is 60 years (see Appendix C). In Great Britain (dark gray, dotted line), participation is highest for the oldest workers. When comparing, for example, participation for workers aged 55-57 years, it becomes obvious that variation between countries is great: in Sweden more than $80 \%$ participate, while these are less than $40 \%$ in Poland.

Including the information whether individual workers participate at the labor market, does not consider the possibility that older workers reduce their participation, measured in work hours, before withdrawing from the labor market completely. Hence, studying participation at the extensive margin (participation) rather than at the intensive margin (working hours), cannot account for thoughts raised by research showing that jobs bridging between participation and retirement might become more important (Blau 1994; Cahill et al. 2006; Elder \& Pavalko 1993; Gielen 2007; Hayward et al. 1998). We decide to study participation at the extensive margin, because assuming that work hours can be reduced as a means to withdraw from the labor market in a stepwise manner, disregards the fact that a continuous adaption of work hours is often dependent on norms regarding part-time employment. Older workers can adjust their working hours according to their wishes only in countries where part-time employment is offered as an option (to account for this, we include part-time work in a country as a control variable - see below). Our study compares countries where part-time employment is widely considered as a means to reduce work hours (e.g. Germany, the Netherlands) to countries where part-time 
International Journal of Ageing and Later Life

employment is much less as a form of participation (e.g. Slovakia, Hungary, Greece) (see Appendix C). By studying participation rather than work hours, we therefore prevent a bias introduced by the divergent possibility of part-time employment.

\section{Independent Variables: Individual Level}

Job resources and job demands were measured with the following variables. Work organization measures the extent to which the respondents could decide how their work was organized and work pace is operationalized as the extent to which respondents could choose and change the pace of their work. These two variables were measured on a scale between 0 ("I had no influence") and 10 ("I had complete influence"). Physical demand was retrieved from the ISCO-88 codes. We recoded each 4-digit code to its respective 2-digit code; a higher value represents a higher physical demand of the job. Respondents who indicated to work in "armed forces occupations" were coded to the mean 2-digit ISCO code.

Work values include extrinsic and intrinsic motivation. For extrinsic motivation we generated a sum scale, including three items asking respondents to indicate on a scale from 1 ("not important at all") to 5 ("very important") how important it was for them if they were choosing a job to have (a) a secure job; (b) a high income; and (c) good promotion opportunities. Intrinsic motivation was measured with the statement "the job enables them to use own initiative" ( $1=$ not important at all; $5=$ very important).

\section{Independent Variables: National Level}

The availability and generosity of welfare state benefits is indicated with a number of variables (see Appendix C). The official retirement age is the age a person may or must retire, without being subject to deductions from pensions. The official age at retirement is regarded separately for men and women. The range of the variable was recoded; the value zero refers to a retirement age of 65 years. Countries in which the retirement age is below 65 have values smaller than zero and countries with a higher retirement age have values greater than zero. Mean retirement age in a country was included to assess whether individuals in countries with a higher average retirement age participate longer. We use the minimum contribution period that provides information on how long individuals need to contribute 
to the social benefit system in order to be eligible for pension benefits. The net replacement rate (for a standard pensioner of 65 years who worked 40 years with average income) measures the height of the pension as a percentage of prior earnings; it is dependent on prior earnings, the composition of the household, or other household member's earnings (see e.g., Blöndal \& Scarpetta 1999; Keck et al. 2009; OECD 2011). The minimum pension levels measures the minimum pension provision for pensioners with a certain contribution period, who have pension claims that are below the minimum defined threshold. The expenditures on old age indicate the public expenditures on pensions as a percentage of the GDP.

Regarding the labor market related characteristics, we operationalized the employment protection legislation as a measure for both the procedures and costs associated with the dismissal and hiring of workers. The employment rate for older workers referred to the labor market participation of workers between age 55 and 64 . We also considered the fraction of the old population, this is the percentage of the population that is older than 65 in a country.

\section{Control Variables}

In prior research, several individual characteristics were included in analyses when investigating retirement age or older workers' participation. We included these variables as control variables; descriptive statistics can be found in Appendix A. We distinguished eight age groups. Gender was measured by a dummy variable referring to male respondents. Education was measured as the formal education in years; more than 20 years of education were recoded to the maximum value of 20 years. Tenure is the length of employment in the current (last) organization in years. Health is asked on a five-point scale ranging from "very good" to "very bad." We take the two categories "bad" and "very bad" together (because of few cases), and distinguish three dummy variables: "very good health," "good," and "fair health." Having a "bad/very bad health" constitutes the reference category. A bad health might have preceded nonparticipation, but it could also appear afterwards. According to OECD standards, full-time is a dummy variable indicating whether respondents work(ed) more than 30 hours per week in their current/last employment, this dummy takes value zero if they worked part-time. Self-employment (or working in a family business) is opposed to being employed in a firm. 
International Journal of Ageing and Later Life

We included a dummy variable indicating whether respondents were ever unemployed and seeking for work for a period of more than three months, because unemployment can be an indication of a disrupted career that forces older workers to work longer at old age. The industry of the (last) employment was measured in six categories; "Agriculture, Mining," "Manufacturing," "(Electricity, gas and water) Supply, Construction, Trade" (reference category), "Service," "Public, Community" and "Education, Health." Last we controlled for whether respondents had a partner and whether they had children below 12 years living in the household. Income is calculated with the variables measuring monthly household income and the percentage of income the respondent contributes to it. Household income was asked in twelve categories and each category was recoded to the respective income in Euro. While the higher bound value was taken for the lowest category (150 Euro or less), the lower bound value was taken for the highest category (10,000 Euro or more). For all other categories, the category mean was considered as the monthly household income. The household income was multiplied with the percentage the respondent contributes to it in order to retrieve individual monthly income. This measure was transferred to a logarithmic scale.

At the country level, prior research mostly included the GDP per capita and the Gini-coefficient to assess the relation with retirement age or participation. We therefore controlled in our analyses for gross domestic product (GDP) per capita in 1000 Euro because richer countries may on average have more opportunities to afford stopping to work at an earlier age than poorer countries. As a measure for income inequality (Gini), we included the Gini-coefficient. Furthermore, we control for the incidence of part-time work in a country, measured as the part-time workers as a percentage of the total employment. We do this to control for the fact that individuals can reduce their working hours in order to retire in a gradual way, especially in countries where part-time work is common.

\section{Methods}

\section{Imputation}

For all variables that have missing values, we imputed the missing values with imputation by chain equations in Stata 11 (StataCorp 2009). 
This means that all variables in the imputation model are used to predict all the other variables. In the imputation equations, we included all variables that are used in the later regressions to predict participation. Appendix A shows descriptive statistics for the sample with and without imputation. Only for those variables that were imputed (i.e. missing observations, those where $\mathrm{N}<15,045$ ) we reported the mean and standard deviation for the imputed sample (right columns). From this table, it is comprehensible which variables have been imputed (i.e. education, tenure, health, full-time, self-employed, the industry of employment, partner, children, income and the individual level independent variables) and that the mean of the imputed sample and the original sample hardly differ. We analyzed the eleven imputed datasets together with the original dataset and report the average relative variance increase due to nonresponse (RVI) in the results, which indicates to what extent the imputed data files vary.

\section{Data Analysis}

Given the hierarchical structure of our data, with individuals nested in countries, we specified two levels and apply a multilevel framework (e.g. Goldstein 1999). The advantage of using a multilevel framework in our case was that hierarchical models could take into account the layered (nested) structure of the data. Measuring errors were specified at each of the two levels. In this way, the error terms take into account that the individual observations within countries may be more alike than individual observations between countries. This means that individual participation behavior in for example Sweden might be more comparable to other older workers in Sweden, than a worker's participation in Sweden is to a worker's participation in Germany. Because we study the participation of older workers, we ran logistic multilevel regression in Stata 11. Besides the threshold of being in retirement for a maximum of ten years, for which we report the results in the regression tables, we performed robustness checks for participation if the threshold is set at a five-year retirement. We discuss these results if they differ from these main results with the ten-year retirement threshold.

In general, our regression equation can be specified in the following way.

$$
Y_{i j}=\gamma_{00}+X_{i j} \gamma_{i j}+Z_{j} \gamma_{j}+u_{j}+\varepsilon_{i j}
$$


International Journal of Ageing and Later Life

Where $X_{i j}$ is the vector constituting all individual independent and individual control variables on the lower level, that is, the individual level, and $Z_{j}$ the vector including all institutional independent and institutional control variables on the higher level, that is the country level. The terms $u_{j}$ and $\varepsilon_{\mathrm{ij}}$ signify the error terms on the higher and the lower level, respectively. This means that this model corrects for the fact that individuals might be more similar within countries than between countries. We do not include random slopes for coefficients, because we do not have explicit assumptions about how associations differ between countries. In the following analyses, we only included the institutional variables separately to the individual-level model. We did this for two reasons. Firstly, the institutional characteristics might be highly correlated and produce colinearity in the model (see Appendix B for correlations). Adding them separately prevented this problem. Secondly, by including several predictors on the country level, standard errors of higher-level variables might be inflated and provide unreliable estimations (Gelman \& Hill 2007).

\section{Results}

Tables 1 and 2 show the multilevel analysis. We include the control variables (Model 1) and then income (Model 2). To this we add the individual work-related variables, both separately and in combination (Model 3). Because the coefficients as reported in Model 2 do not change substantially when including the work-related variables, we only report the coefficients of the work-related variables in Model 3. In Table 3, we include the country-level variables successively and separately to the model including all individual level control variables and work-related variables. We report odds ratios; odds ratios above one signify a positive relation with labor market participation, and odds ratios below one a negative relation.

Holding constant for all other variables in the model, Table 1 (Model 1) shows that individuals in older age groups are less likely to participate than those in younger age groups. Specifically, individuals above the age of 63 are less likely to participate than those between 61 and 63 years. The odds of participating in the age group 64-65 are, for example more than $60 \%$ lower than the odds of participating at age 61-63. On the contrary, individuals younger than 61 are more likely to participate than 
Table 1. Odds ratios, multilevel logistic regression on participation $(0 / 1)$, results for original sample and eleven imputed models $(\mathrm{N}=15,045)$

\begin{tabular}{|c|c|c|c|c|}
\hline & \multicolumn{2}{|c|}{ Model 1} & \multicolumn{2}{|c|}{ Model 2} \\
\hline & OR & & OR & \\
\hline \multicolumn{5}{|l|}{ Age group (ref.: 61-63 years) } \\
\hline $45-49$ & 51.137 & $* * *$ & 52.095 & $* * *$ \\
\hline $50-54$ & 24.559 & $* * *$ & 25.365 & $* * *$ \\
\hline $55-57$ & 10.828 & $* * *$ & 10.473 & $* * *$ \\
\hline $58-60$ & 3.672 & $* * *$ & 3.655 & $* * *$ \\
\hline $64-65$ & 0.384 & $* * *$ & 0.400 & $* * *$ \\
\hline $66-67$ & 0.210 & $* * *$ & 0.227 & $* * *$ \\
\hline $68-70$ & 0.100 & $* * *$ & 0.114 & $* * *$ \\
\hline Gender (Male = 1) & 1.308 & + & 1.008 & \\
\hline Education (in years) & 0.954 & & 0.899 & ** \\
\hline Education squared & 1.007 & $* * *$ & 1.007 & $* * *$ \\
\hline Tenure & 1.080 & $* * *$ & 1.054 & $* * *$ \\
\hline \multicolumn{5}{|l|}{ Health (ref.: very bad, bad) } \\
\hline Fair & 4.488 & $* * *$ & 4.637 & $* * *$ \\
\hline Good & 7.273 & $* * *$ & 7.360 & $* * *$ \\
\hline Very good & 8.923 & $* * *$ & 8.842 & $* * *$ \\
\hline Full-time employed $(0 / 1)$ & 0.719 & $* * *$ & 0.720 & $* * *$ \\
\hline Gender * full-time & 1.298 & + & 1.181 & \\
\hline Self-employed (0/1) & 2.165 & $* * *$ & 2.307 & $* * *$ \\
\hline Ever unemployed $>3$ months & 1.068 & & 1.240 & $* * *$ \\
\hline \multicolumn{5}{|c|}{ Industry (ref.: Supply, construction, trade) } \\
\hline Agriculture, mining & 0.741 & ** & 0.770 & * \\
\hline Manufacturing & 0.768 & $* *$ & 0.740 & $* * *$ \\
\hline Service & 0.985 & & 0.888 & \\
\hline Public, community & 1.159 & + & 1.075 & \\
\hline Education, health & 1.372 & $* * *$ & 1.174 & + \\
\hline Partner $(0 / 1)$ & 0.994 & & 1.260 & $* * *$ \\
\hline Child < 12 yrs $(0 / 1)$ & 0.492 & $* * *$ & 0.529 & $* * *$ \\
\hline Gender * child & 4.949 & $* * *$ & 3.977 & $* * *$ \\
\hline Income (log) & & & 1.764 & $* * *$ \\
\hline Variance country level (log) & -1.377 & 0.326 & -0.844 & 0.322 \\
\hline$\sigma_{\mathrm{u}}$ & 0.502 & 0.082 & 0.656 & 0.105 \\
\hline$\rho($ rho $)$ & 0.071 & 0.022 & 0.116 & 0.033 \\
\hline Observations & 15,045 & & 15,045 & \\
\hline Countries & 21 & & 21 & \\
\hline Average RVI & 0.042 & & 0.034 & \\
\hline
\end{tabular}

${ }^{* * *} \mathrm{p}<0.001 ;{ }^{* *} \mathrm{p}<0.01 ;{ }^{*} \mathrm{p}<0.05 ;+\mathrm{p}<0.1$. 
International Journal of Ageing and Later Life

Table 2. Odds ratios, multilevel logistic regression on participation $(0 / 1)$, results for original sample and eleven imputed models $(\mathrm{N}=15,045)$ (holding constant for all variables as in Model 2)

\begin{tabular}{|c|c|c|}
\hline & \multicolumn{2}{|c|}{ Model 3} \\
\hline & OR & \\
\hline \multicolumn{3}{|c|}{ Work-related variables (separately) } \\
\hline Intrinsic motivation & 0.952 & \\
\hline Extrinsic motivation & 0.990 & \\
\hline Work organization & 1.034 & $* * *$ \\
\hline Work pace & 1.027 & $* * *$ \\
\hline Physical demand & 1.002 & \\
\hline \multicolumn{3}{|c|}{ Work-related variables (combined) } \\
\hline Intrinsic motivation & 0.924 & * \\
\hline Extrinsic motivation & 1.030 & \\
\hline Work organization & 1.034 & $* *$ \\
\hline Work pace & 1.010 & \\
\hline Physical demand & 1.003 & * \\
\hline \multicolumn{3}{|l|}{ Combined model } \\
\hline Variance country level (log) & -0.879 & 0.322 \\
\hline$\sigma_{\mathrm{u}}$ & 0.644 & 0.104 \\
\hline$\rho$ (rho) & 0.112 & 0.032 \\
\hline Observations & 15,045 & \\
\hline Countries & 21 & \\
\hline Average RVI & 0.038 & \\
\hline
\end{tabular}

${ }^{* * *} \mathrm{p}<0.001 ;{ }^{* *} \mathrm{p}<0.01 ;{ }^{*} \mathrm{p}<0.05 ;+\mathrm{p}<0.1$.

those between age 61 and 63. Regarding the other control variables, we see that men participate significantly more than women, but this association disappears after including the interactions, and after including income. Education is related to participation in a decreasing u-shaped way. This indicates that in general the likelihood to participate decreases with increasing education; however, both lower and higher educated are more likely to participate compared to older workers with medium education. Tenure is positively related to participation. Older individuals who worked longer in the same organization are more likely to participate, holding constant for their age. Furthermore, we assess that the odds of healthier older workers to participate are higher compared to those with 
"very bad or bad" health. Respondents who work full-time have lower odds to participate compared to part-time workers. Additionally, the interaction between working full-time and being male appears to be marginally significant in Model 1, indicating that men who work full-time are more likely to participate. This relation is not significant when controlling for income (Model 2). Furthermore, older workers who are self-employed have higher odds to participate than wage-earners. Having been unemployed for longer than three months is positively (and in Model 2 significantly) related to participation. We find differences between the industries of employment. Older workers in "Agriculture and mining" and "Manufacturing" are less likely to participate than those working in "Supply, construction and trade" (reference), while those in "Education and health" are more likely to participate in the labor market. Last, having a partner is positively related to participation (Model 2). This means that older people with a partner are more likely to participate in the labor market. Furthermore, as the interaction between having children and gender illustrates, older women with a child that is younger than twelve years in the household appear to be less likely to participate, while older men who have a child are more likely to participate. These outcomes are the same in our robustness checks with the five-year retirement horizon and replicate the findings of earlier studies. Model 2 shows a positive and significant association between income and participation. This means that older individuals with a higher income are more likely to participate.

In Model 3 of Table 2, the work characteristics are included separately (first block) and combined (second block). This means that we first add each work-related characteristic separately to the control variables as in Model 2 (first block), and then add all work characteristics at once to the model (second block). Having autonomy in the work place (with respect to both work organization and work pace) positively relates to the likelihood of participation. Because the variables are highly correlated, the impact of work pace is not significant if both variables are included. These results mainly confirm the autonomy hypothesis, stating that workers with more autonomy are more likely to participate. The relation between physical demand and participation is not significant when included separately. The coefficient is even positive if other work characteristics are taken into account (see second block). This does not support our hypothesis that 
International Journal of Ageing and Later Life

workers with higher physical demands are more likely to retire. Furthermore, our results refute the work values hypothesis; they show that intrinsic motivation is negatively related to the likelihood to participate (second block). This indicates that workers with a higher intrinsic motivation generally report a lower participation in the labor market. Furthermore, extrinsic motivation is not found to be significantly related to participation, indicating that older workers' participation is independent of their extrinsic motivation.

In Table 3, the national characteristics are added separately to the model with all earlier discussed variables (Model 3). The three national level control variables are associated to the labor market participation of older workers. GDP per capita has a negative relation with labor market participation; income inequality has a marginally significant positive relation with labor market participation; and the percentage of part-time workers in a country is also positively (and marginally significantly) related to older workers' labor market participation.

In the next steps, we investigate the relation of the institutional variables with the labor market participation of older workers as summarized in the pension generosity hypothesis. The official retirement age (for men and women) does not relate significantly to older workers' participation. The mean age at which people retire in a country is positively related to participation (this association is stronger if the five year retirement period is chosen). This means that, holding constant for all the individual characteristics, workers who live in countries with a higher mean actual retirement age are more likely to participate in the labor market. The model shows that the minimum contribution period is not significantly related to participation at the ten-year time horizon for retirement, while it is negative and significant at the five-year retirement period (not reported). And, the net replacement rate is negatively but not significantly related to the labor market participation of older workers at the ten-year period, but it becomes significant at the five-year time horizon (not reported). The minimum pension level in a country appears to be negatively and significantly related to individual's labor market participation. This means that the odds for older workers to participate decrease with an increasing net replacement rate and also if the minimum pension level is higher. Higher expenditures on old age are negatively related to participation 
Hello pension, goodbye tension?

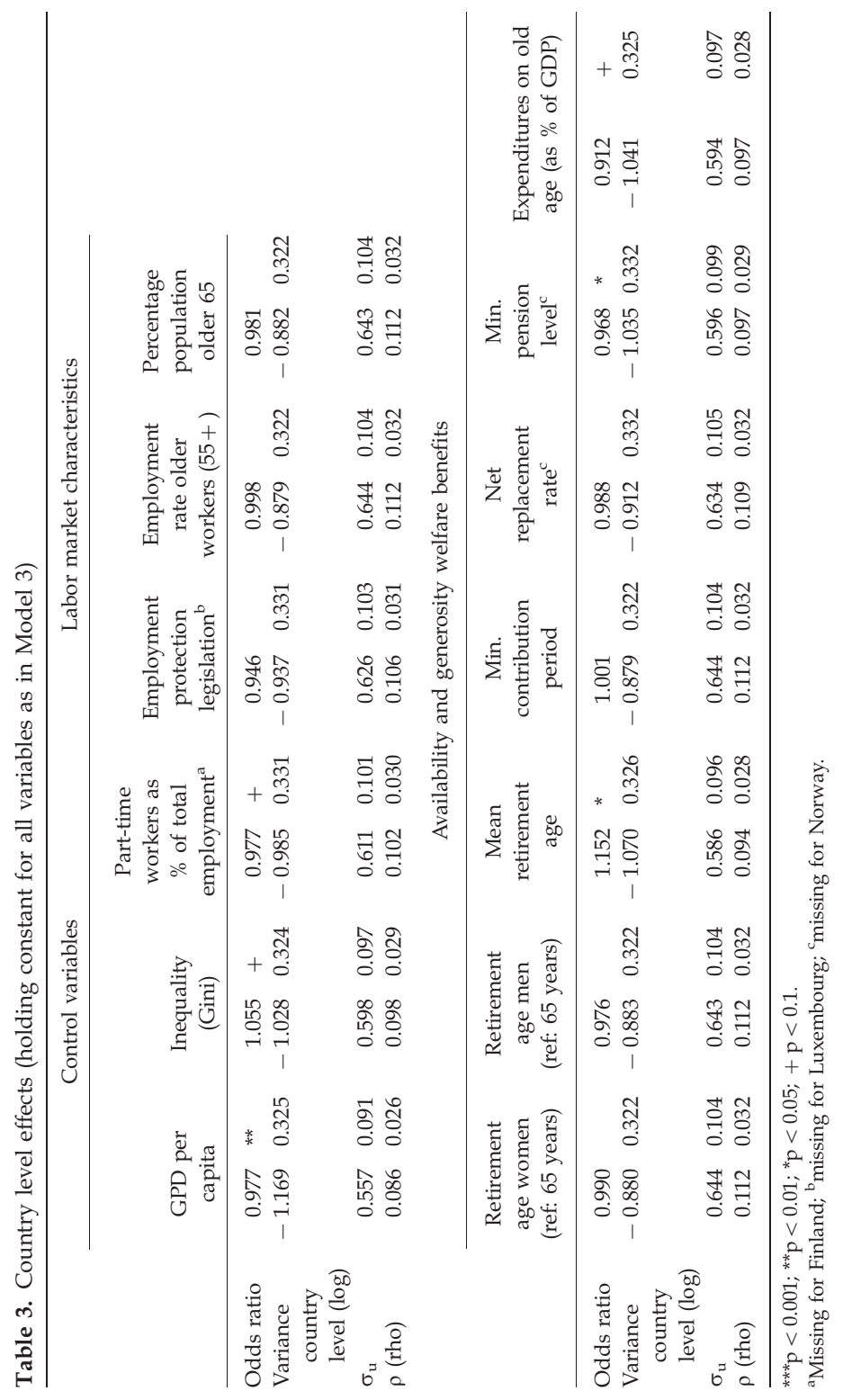


International Journal of Ageing and Later Life

(marginally significant). This means that higher expenditures for older people decrease the odds for older workers to participate. Put together, these results provide some support for the pension generosity hypothesis, stating that in countries with more generosity the labor market participation of older workers is lower.

Finally, we included several indicators relating to the labor market situation. Employment protection legislation is not significantly related to older people's labor market participation. Also, a higher employment rate of older workers in a country does not significantly relate to their labor market participation. Finally, the percentage of people older than 65 years in a country is not significantly related to participation. The outcomes are similar for both time horizons. The institutional support hypothesis can therefore not be supported.

\section{Conclusion and Discussion}

As the average age of the population of European countries increases, the policy question of what circumstances explain the labor participation of older workers becomes more and more relevant. Knowing more about the work and institutional characteristics encouraging and discouraging the willingness to work among the older age groups has the potential to provide means of supporting the labor market participation of these workers. The present article aimed at identifying such characteristics using a framework where individuals take (rational) decisions. The findings basically showed that while some of the work aspects increased the likelihood of labor market participation of older workers, the institutional characteristics mainly decreased the likelihood of their participation.

These findings have some practical implications. Most of all, it means that both employers and governments can play a role in stimulating the labor participation of older workers. Employers can do this by offering attractive work places that provide autonomy to older workers. Here, we have focused on characteristics of the job such as discretion in the organization of work. Nevertheless, employers can also use other human resource policies to be attractive for older workers. Such policies can for example include mentoring relationships, but also an interesting and stimulating workplace through, for example, learning and development might reduce older 
workers' intention to retire (Münderlein et al. 2013). As the results for the pension generosity showed, individual workers seem less prone to participate actively in the labor market if the monetary benefits from welfare are higher. This generally indicates that generous monetary welfare benefits alone do not keep people in the labor market. In order to increase older workers' labor market participation, governments might decrease the benefits, especially those stimulating early retirement. Recent discussions move in that direction: multiple European countries consider decreasing pension benefits or making early retirement fiscally less attractive. Such policies change the balance between the utility and disutility that people derive from work and retirement. Restricting pension policies may be a viable means of keeping older workers in the workforce. There are, however, some potential downsides. For example, decreasing the generosity may mainly have an impact on the participation of those who earn less and it may lead to unintended effects on those remaining in the workforce, like increased levels of work stress and decreasing work satisfaction. Future studies may be directed at investigating whether such effects occur.

The analyses presented here showed that the factors related to the labor market participation of older workers could be framed in terms of costs and benefits and several of the previously found associations where replicated in this study. Nevertheless, some results of this study differ and some of the expected hypotheses were refuted. An explanation for missing associations between national level variables and older workers' participation may be the convergence of social policies within the European Union. For example, the official retirement age is increasingly similar due to EU level agreements. In 2004, the lowest official retirement age can be found in the Czech Republic, with 57 years for women and 60 years for men, and in France with 60 years for both men and women. The highest official retirement age is 67 years for both men and women in Norway (see also Appendix C). Furthermore, out of the 21 countries included in our study, the official retirement age is 65 years for women in ten countries. For men, in two thirds of the countries the official retirement age is 65 . This shows that the variation in the official retirement age is generally very small.

Some of the findings of the present study differed from earlier ones. In contrast with most other studies (Blekesaune \& Solem 2005; Hayward 
et al. 1989, 1998; Schils 2008), educational level was negatively associated with the labor market participation of older workers. A possible explanation for this difference concerns the number of countries included. Only Fischer and Sousa-Poza's (2006) study, which also included a larger sample of countries, reports a result comparable with ours. In additional analyses (results available upon request), we included a random slope for education; analyses showed that educational level varied significantly across countries. This suggests that the impact of education differs between these countries. This should be taken into account in future studies investigating the labor market participation of older workers as it points in the direction of institutional differences and effects.

Regarding the negative relation between full-time employment and participation, our finding differed from prior research. Hayward and colleagues (1998) found that full-time working employees were less likely to retire than unemployed and Schils (2008) assessed that more working hours were related to a lower likelihood of (early) retirement. There may be two reasons for this difference. First, older workers may increasingly choose to work part-time instead of full-time, as they get older. If older workers are increasingly participating part-time, part-time employment (rather than full-time employment) would be positively related to participation. This rationale is supported by the fact that part-time work in Europe is mainly relevant for older and younger employees (Eurostat 2012). Recent research showed that older workers increasingly used part-time employment as a possibility to bridge work and retirement (Blau 1994; Cahill et al. 2006; Elder \& Pavalko 1993; Gielen 2007; Hayward et al. 1998). This way, labor supply of older workers generally increases, but only at the extensive margin, while labor supply decreases when considering the working hours, that is, at the intensive margin (Gielen 2007). Especially in the Netherlands, and to a lesser extent also in the UK or Germany, part-time work is an alternative to fulltime employment. A second interpretation concerns the measurement of how many working hours are considered as full-time employment, which differs across these studies.

Apart from the previously mentioned suggestions for future research, the present study can be extended in a number of directions. For instance, this study aimed at including work characteristics to explain differences in labor market participation of older workers. Due to data limitations, 
we were only able to include some of these characteristics. Including more work-related aspects, and in particular organizational policies, will increase our understanding even further. These work-related characteristics should therefore also be considered in future research. While we implicitly assumed that individual and work characteristics were similarly important for older workers independent of their age, it might be interesting for further research to develop theoretical arguments why some work characteristics play a greater role for the "younger older" workers, when compared to the "older older" workers. Related to that, future studies might consider two things. First, we use a measure for intrinsic and extrinsic motivation that is not taking into account whether employees can actually realize their motivations. It may be the case that employees for example find it very important to have an interesting job, but do not have this at their current workplace. In such a case, even though they have a high motivation, this misfit with what they want might lead to a lower work attachment (see e.g., Münderlein et al. 2013). Even though (intrinsic or extrinsic) motivation is generally measured with questions comparable to ours, future research might take into account that motivations might or might not be realized. Second, further research might investigate the role of personal resources and for example extend on this by including other activities than work, like voluntary work and informal care. Third, our operationalization of the dependent variable labor market participation subjoined different forms of withdrawal from the labor market in the category of non-participation, such as disabled persons or retired individuals. In future research it might be interesting to make a distinction between these possible forms of withdrawal (Blekesaune \& Solem 2005). Finally, we investigated the effects of a number of institutional characteristics. One of the detriments of comparing countries is that one cannot provide an in-depth analysis of the welfare benefits or labor market policies in each of the countries. Future studies might, therefore, find it worthwhile including even more fine-grained indicators of countries' pension systems to investigate how this relates to the participation of older workers. In combination, this has the potential to combine different goals at different levels, namely the national (a sustainable pension systems), the organizational (have a satisfied and productive workforce), and the individual (having a challenging job). 
International Journal of Ageing and Later Life

\section{Acknowledgements}

This research is funded by the project "Productive in multiple ways: In search for activating institutions," Stichting Instituut Gak (SZ2025).

\section{Corresponding Author}

Ferry Koster, Department of Sociology, Faculty of Social Sciences, Erasmus University, Rotterdam, PO Box 1738, 3000 DR Rotterdam, The Netherlands.

Email: koster@fsw.eur.nl

\section{References}

Bakker, A. B. \& Demerouti, E. (2006). The job demands-resources model: State of the art. Journal of Managerial Psychology 22: 309-328.

Beehr, T. A. (1986). The process of retirement. A review and recommendations for future investigation. Personnel Psychology 39: 31-55.

Blau, D. M. (1994). Labor force dynamics of older men. Econometrica 62: 117-156.

Blau, D. M. (1998). Labor force dynamics of older married couples. Journal of Labor Economics 16: 595-629.

Blekesaune, M. \& Solem, P. E. (2005). Working conditions and early retirement: A prospective study of retirement behavior. Research on Aging 27: 3-30.

Blöndal, S. \& Scarpetta, S. (1999). The retirement decision in OECD countries. Paris: OECD. OECD Economics Department Working Papers 202.

Cahill, K. E., Giandrea, M. D. \& Quinn, J. F. (2006). Retirement pattern from career employment. The Gerontologist 46: 514-523.

Coile, C. (2004). Retirement incentives and couples' retirement decisions. Topics in Economic Analysis \& Policy 4: 1-28.

Coleman, J. S. (1990). Foundations of Social Theory. Cambridge, MA: Harvard University Press.

Damman, M., Henkens, K. \& Kalmijn, M. (2009). Retirement of Dutch Male Older Workers. The Role of Mid-Life Educational, Work, Health, and Family Experiences. Tilburg, The Netherlands: Netspar. 
Dentinger, E. \& Clarkberg, M. (2002). Informal caregiving and retirement timing among men and women: Gender and caregiving relationships in late midlife. Journal of Family Issues 23: 857-879.

Elder, G. H. \& Pavalko, E. K. (1993). Work careers in men's later years: Transitions, trajectories, and historical change. Journal of Gerontology 48: 180-191.

Esping-Andersen, G. (1990). The Three Worlds of Welfare Capitalism. Princeton, NJ: Princeton University Press.

European Commission. (2001). Council Decision of 19 January 2001 on Guidelines for Member States' Employment Policies for the Year 2001. Luxembourg: European Commission.

European Commission. (2009). Longer Working Lives through Pension Reforms. Luxembourg: European Commission.

European Social Survey Round 2 Data. (2004). Data file edition 3.3. Norwegian Social Science Data Services. Norway: Data Archive and distributor of ESS data.

Eurostat (2012). Statistics Database. Available on http://epp.eurostat. ec.europa.eu/portal/page/portal/statistics/search_database (Accessed: September 23, 2012).

Eurostat (2013). Statistics Database. Available on http://epp.eurostat. ec.europa.eu/portal/page/portal/statistics/search_database (Accessed: April 4, 2013).

Fasang, A. E., Geerdes, S. \& Schömann, K. (2012). Which type of job mobility makes people happy? A comparative analysis of European welfare regimes. International Sociology 27: 349-383.

Feather, N. T. \& O'Brien, G. E. (1986). A longitudinal analysis of the effects of different patterns of employment and unemployment on schoolleavers. British Journal of Psychology 77: 459-479.

Fischer, J. A. V. \& Sousa-Poza, A. (2006). The institutional determinants of early retirement in Europe (pp. 1-29). St. Gallen, Switzerland: University of St. Gallen Discussion Paper 2006-08.

Forma, P. (2008). Work, family and intentions to withdraw from the workplace. International Journal of Social Welfare 18: 183-192.

Frey, B. S. (1997). Not Just for the Money. An Economic Theory of Personal Motivation. Brookfield/Cheltenham: Edward Elgar.

Gelman, A. \& Hill, J. (2007). Data Analysis Using Regression and Multilevel/ Hierarchical Models. New York: Cambridge University Press. 
International Journal of Ageing and Later Life

Gielen, A. C. (2007). Working hours flexibility and older workers' labor supply. Oxford Economic Papers 61: 240-274.

Goldstein, H. (1999). Multilevel Statistical Models. London: Institute of Education.

Hayward, M. D., Friedman, S. \& Chen, H. (1998). Career trajectories and older men's retirement. Journal of Gerontology B 53: 91-103.

Hayward, M. D., Grady, W. R., Hardy, M. A. \& Sommers, D. (1989). Occupational influences on retirement, disability, and death. Demography 26: 393-409.

Hofäcker, D. \& Pollnerova, S. (2006). Late careers and career exits. An international comparison of trends and institutional background patterns. In H.-P. Blossfeld, S. Buchholz \& D. Hofäcker (eds.), Globalization, Uncertainty and Late Careers in Society (pp. 25-53). Abingdon: Routledge.

Ingelhart, R. (1990). Culture Shift in Advanced Industrial Society. Princeton, NJ: Princeton University Press.

Keck, W., Hessel, P. \& Saraceno, C. (2009). Multilinks. Database on Intergenerational Policy Indicators. Methodological Report. Berlin: Social Science Research Center.

Kim, J. (2009). Early retirement in the three types of welfare states. Research on Aging 31: 520-548.

Knoop, R. (1994). Work values and job-satisfaction. Journal of Psychology 128: 683-690.

Komp, K. \& Béland, D. (2012). Guest editorial: Balancing protection and productivity: International perspectives on social policies for older people. International Journal of Social Welfare 21: S1-S7.

Lambert, E. G., Hogan, N. L. \& Barton, S. M. (2001). The impact of job satisfaction on turnover intent: A test of a structural measurement model using a national sample of workers. The Social Science Journal 38: 233-350.

Liefbroer, A. C. (2009). European's Opinions on the Timing of Retirement. European Policy Brief \#2. Available online: http://www.multilinksproject.eu/uploads/papers/0000/0024/Second_Policy_Brief_MULTILINKS. pdf (last accessed 3 Feb 2014).

Mein, G., Martikainen, P., Stansfeld, S. A., Brunner, E. J., Fuhrer, R. \& Marmot, M. G. (2000). Predictors of early retirement in British civil servants. Age and Ageing 29: 529-536. 
Hello pension, goodbye tension?

Münderlein, M., Ybema, J. F. \& Koster, F. (2013). Happily ever after? Explaining turnover and retirement intentions of older workers in the Netherlands. Career Development International 18: 548-568.

OECD. (2006). Ageing and Employment Policies: Live Longer, Work Longer. Paris: OECD.

OECD. (2011). Pensions at a Glance 2011: Retirement-Income Systems in OECD and G20 Countries. Paris: OECD.

Schils, T. (2008). Early retirement in Germany, the Netherlands and the United Kingdom: A longitudinal analysis of individual factors and institutional regimes. European Sociological Review 24: 315-329.

Shultz, K. S., Morton, K. R. \& Weckerle, J. R. (1998). The influence of push and pull factors on voluntary and involuntary early retirees' retirement decision and adjustment. Journal of Vocational Behavior 53: 45-57.

Siegrist, J. \& Wahrendorf, M. (2010). Quality of work, health and early retirement: European comparisons. Mannheim: Mannheim Research Institute for the Economics of Aging. Working Paper 224-2010.

Siegrist, J., Wahrendorf, M., Von dem Knesebeck, O., Jürges, H. \& BörschSupan, A. (2006). Quality of work, well-being, and intended early retirement of older employees - baseline results from the SHARE Study. European Journal of Public Health 17: 62-68.

Smith, D. R., Holtom, B. C. \& Mitchell, T. R. (2011). Enhancing precision in the prediction of voluntary turnover and retirement. Journal of Vocational Behavior 79: 290-302.

StataCorp. (2009). Stata Multiple Imputation Reference Manual: Release 11. Statistical Software. College Station, TX: StataCorp LP.

Van Dalen, H. P., Henkens, K., Henderikse, H. \& Schippers, J. (2006). Dealing with an ageing labour force: What do European employers expect and do? The Hague: NIDI. Report No. 73.

Van den Broeck, A., Van Ruysseveldt, J., Smulders, P. \& De Witte, H. (2011). Does an intrinsic work value orientation strengthen the impact of job resources? A perspective from the Job Demands-Resources Model. European Journal of Work and Organizational Psychology 20: 581-609.

Van Oorschot, W. \& Jensen, P. H. (2009). Early retirement differences between Denmark and The Netherlands. A cross-national comparison 
International Journal of Ageing and Later Life

of push and pull factors in two small European welfare states. Journal of Ageing Studies 23: 267-278.

Von Bonsdorff, M. E. (2009). Intentions of early retirement and continuing to work among middle-aged and older employees. University of Jyväskylä. Jyväskylä Studies in Business and Economics 83. Jyväskylä: Jyväskylä University Printing House.

Walker, A. \& Maltby, T. (2012). Active ageing: A strategic policy solution to demographic ageing in the European Union. International Journal of Social Welfare 21: S117-S130.

Wang, M. \& Shultz, K. S. (2009). Employee retirement. A review and recommendations for future investigation. Journal of Management 36: $172-206$.

Wise, D. A. (2010). Facilitating longer working lives: International evidence in why and how. Demography 47: 131-149. 
Hello pension, goodbye tension?

Appendix A. Descriptive results for original sample and sample with imputed variables

\begin{tabular}{|c|c|c|c|c|c|c|c|}
\hline & \multirow[b]{2}{*}{ Range } & \multicolumn{3}{|c|}{ Original sample } & \multicolumn{3}{|c|}{ Imputed variables } \\
\hline & & Obs. & Mean & SD & Obs. & Mean & SD \\
\hline Participation & $0 / 1$ & 15,045 & 0.55 & & & & \\
\hline \multicolumn{8}{|l|}{ Age group } \\
\hline $45-49$ & $0 / 1$ & 15,045 & 0.23 & & & & \\
\hline $50-54$ & $0 / 1$ & 15,045 & 0.22 & & & & \\
\hline $55-57$ & $0 / 1$ & 15,045 & 0.13 & & & & \\
\hline $58-60$ & $0 / 1$ & 15,045 & 0.12 & & & & \\
\hline 61-63 (ref.) & $0 / 1$ & 15,045 & 0.10 & & & & \\
\hline $64-65$ & $0 / 1$ & 15,045 & 0.07 & & & & \\
\hline $66-67$ & $0 / 1$ & 15,045 & 0.06 & & & & \\
\hline $68-70$ & $0 / 1$ & 15,045 & 0.07 & & & & \\
\hline Gender $($ male $=1)$ & $0 / 1$ & 15,045 & 0.47 & & & & \\
\hline Education (in yrs) & $0-20$ & 14,878 & 11.43 & 3.87 & 15,045 & 11.43 & 3.87 \\
\hline Tenure & $0-65$ & 13,568 & 31.08 & 10.38 & 15,045 & 30.87 & 10.57 \\
\hline \multicolumn{8}{|l|}{ Health } \\
\hline Bad/very bad (ref.) & $0 / 1$ & 15,030 & 0.10 & & 15,045 & 0.10 & \\
\hline Fair & $0 / 1$ & 15,030 & 0.33 & & 15,045 & 0.33 & \\
\hline Good & $0 / 1$ & 15,030 & 0.41 & & 15,045 & 0.41 & \\
\hline Very good & $0 / 1$ & 15,030 & 0.16 & & 15,045 & 0.16 & \\
\hline Full-time employed & $0 / 1$ & 13,198 & 0.83 & & 15,045 & 0.83 & \\
\hline Self-employed & $0 / 1$ & 14,278 & 0.19 & & 15,045 & 0.19 & \\
\hline $\begin{array}{l}\text { Ever unemployed } \\
\quad>3 \text { months }\end{array}$ & $0 / 1$ & 15,045 & 0.24 & & & & \\
\hline \multicolumn{8}{|l|}{ Industry } \\
\hline Agriculture, mining & $0 / 1$ & 13,900 & 0.07 & & 15,045 & 0.08 & \\
\hline Manufacturing & $0 / 1$ & 13,900 & 0.20 & & 15,045 & 0.21 & \\
\hline $\begin{array}{l}\text { Supply, construction, } \\
\text { trade (ref.) }\end{array}$ & $0 / 1$ & 13,900 & 0.19 & & 15,045 & 0.19 & \\
\hline Service & $0 / 1$ & 13,900 & 0.20 & & 15,045 & 0.20 & \\
\hline Public, community & $0 / 1$ & 13,900 & 0.13 & & 15,045 & 0.13 & \\
\hline Education, health & $0 / 1$ & 13,900 & 0.20 & & 15,045 & 0.20 & \\
\hline Partner & $0 / 1$ & 15,001 & 0.75 & & 15,045 & 0.75 & \\
\hline Child $<12$ yrs & $0 / 1$ & 15,028 & 0.08 & & 15,045 & 0.08 & \\
\hline Income (log) & $0-9.21$ & 11,902 & 6.35 & 1.95 & 15,045 & 6.24 & 2.04 \\
\hline
\end{tabular}


International Journal of Ageing and Later Life

Appendix A (Continued)

\begin{tabular}{|c|c|c|c|c|c|c|c|}
\hline & \multirow[b]{2}{*}{ Range } & \multicolumn{3}{|c|}{ Original sample } & \multicolumn{3}{|c|}{ Imputed variables } \\
\hline & & Obs. & Mean & SD & Obs. & Mean & SD \\
\hline \multicolumn{8}{|l|}{$\begin{array}{l}\text { Independent variables } \\
\text { (individual level) }\end{array}$} \\
\hline Intrinsic motivation & $0-4$ & 14,422 & 2.98 & 0.86 & 15,045 & 2.98 & 0.86 \\
\hline Extrinsic motivation & $0-4$ & 14,483 & 2.91 & 0.73 & 15,045 & 2.91 & 0.74 \\
\hline Work organization & $0-10$ & 14,112 & 6.20 & 3.60 & 15,045 & 6.12 & 3.63 \\
\hline Work pace & $0-10$ & 14,071 & 5.79 & 3.68 & 15,045 & 5.72 & 3.70 \\
\hline Physical demand & $10-93$ & 14,062 & 50.26 & 25.48 & 15,045 & 50.91 & 25.52 \\
\hline
\end{tabular}


Hello pension, goodbye tension?

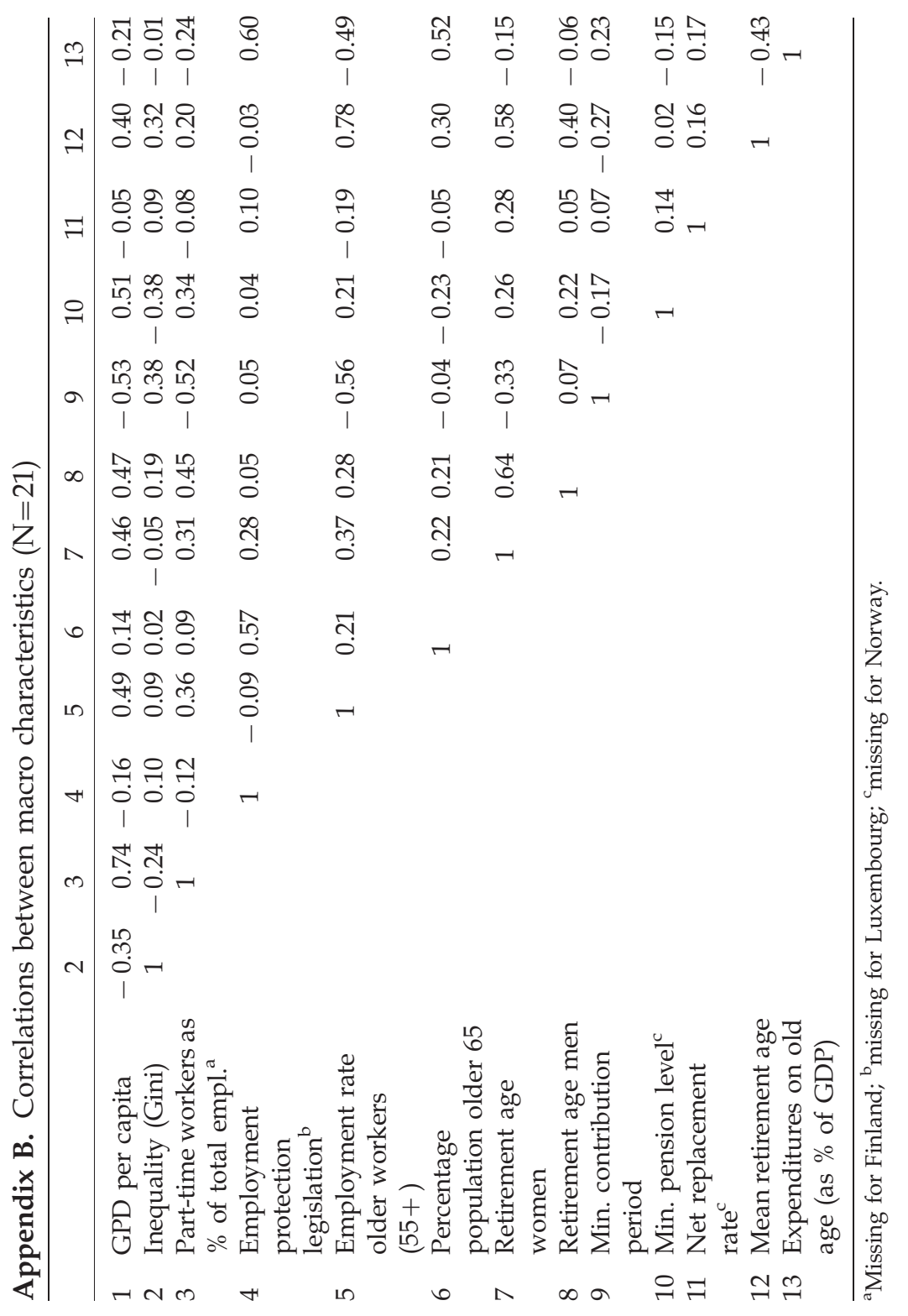


International Journal of Ageing and Later Life

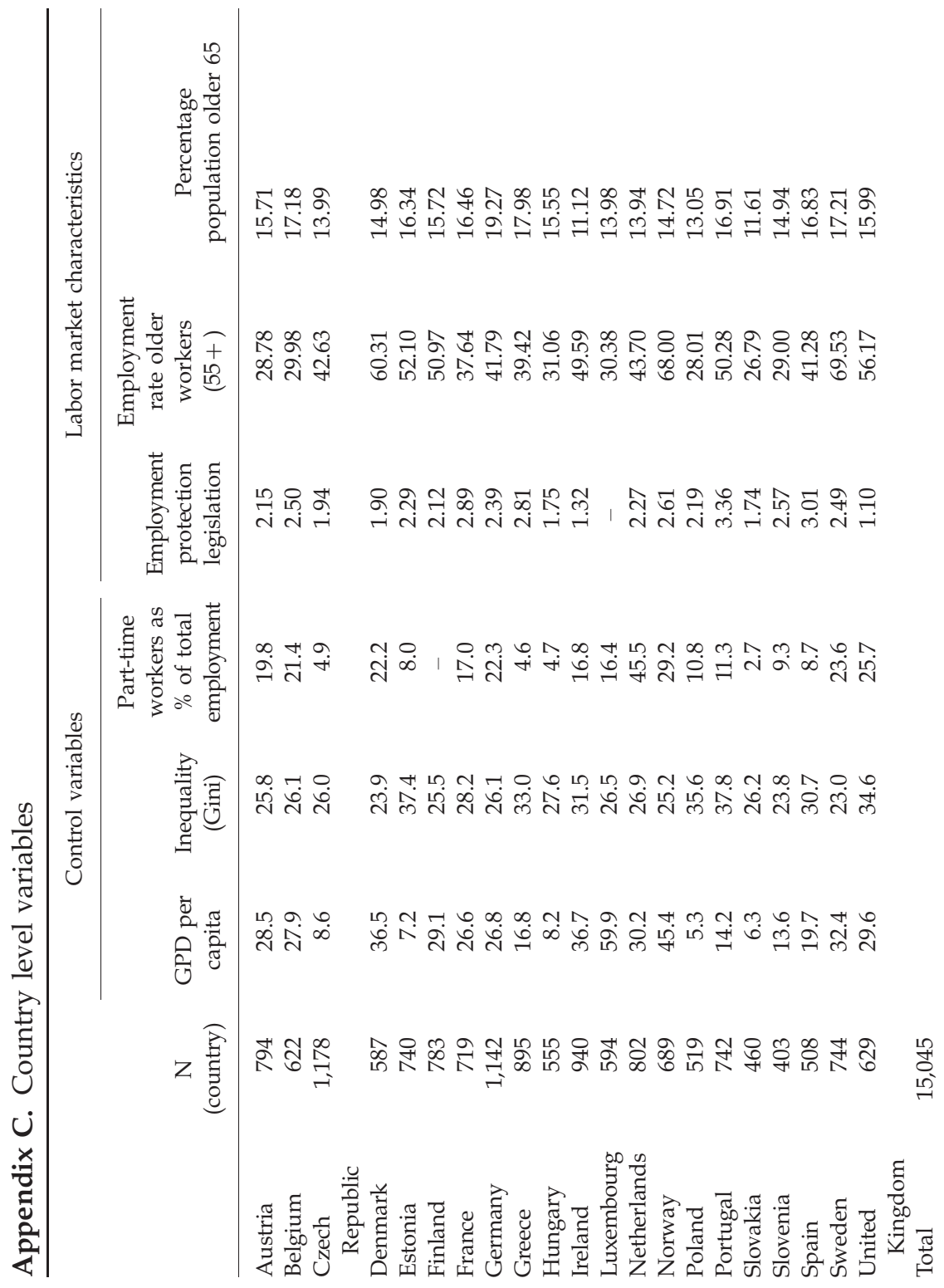


Hello pension, goodbye tension?

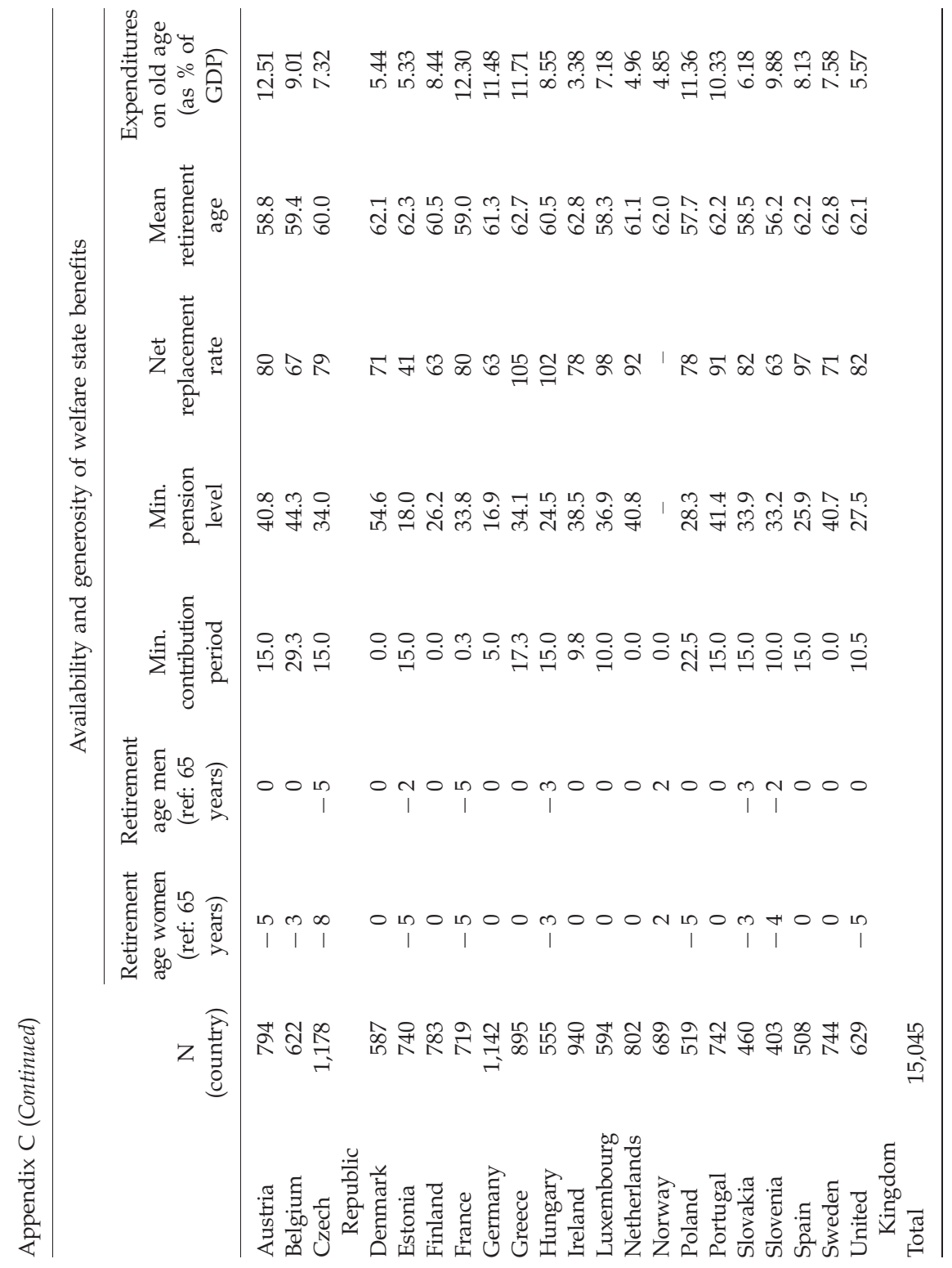

